\title{
Article
}

\section{Vascular and Cardiac Prognostic Determinants in Patients with Gynecological Cancers: A Six-Year Follow-up Study}

\author{
Pietro Scicchitano ${ }^{1, *(\mathbb{D}}$, Marco Tucci $\left.{ }^{2} \mathbb{(}\right)$, Gabriella Ricci ${ }^{3}(0)$, Michele Gesualdo ${ }^{1}\left(\mathbb{D}\right.$, Santa Carbonara $^{3}$, \\ Giuseppe Totaro $^{4}$, Annagrazia Cecere ${ }^{3}$, Rosa Carbonara ${ }^{3}{ }^{(0)}$, Francesca Cortese ${ }^{3}{ }^{(0)}$, Vera Loizzi ${ }^{4}{ }^{\circledR}$, \\ Gennaro Cormio ${ }^{4} \mathbb{D}$, Ettore Cicinelli ${ }^{4}$ and Marco Matteo Ciccone ${ }^{3}$ \\ 1 Cardiology Department, Hospital “F. Perinei” Altamura (BA), ASL BA, 70022 Altamura, Italy; \\ michelegesualdo@libero.it \\ 2 Department of Biomedical Sciences and Human Oncology, University of Bari Aldo Moro, 70124 Bari, Italy; \\ marco.tucci@uniba.it \\ 3 Section of Cardiovascular Diseases, Department of Emergency and Organ Transplantation, University of Bari, \\ 70124 Bari, Italy; gabry.ricci1986@libero.it (G.R.); titticarbo@hotmail.it (S.C.); agcecere@gmail.com (A.C.); \\ rossellacarbonara@hotmail.it (R.C.); francescacortese@hotmail.it (F.C.); \\ marcomatteo.ciccone@uniba.it (M.M.C.) \\ 4 2nd Unit of Obstetrics and Gynecology, Department of Biomedical Science and Human Oncology, University \\ of Bari, 70124 Bari, Italy; cardiologia1985@libero.it (G.T.); vera.loizzi@uniba.it (V.L.); \\ gennaro.cormio@uniba.it (G.C.); ettore.cicinelli@uniba.it (E.C.) \\ * Correspondence: piero.sc@hotmail.it; Tel.: +39-080-547-8791; Fax: +39-080-547-8796
}

check for updates

Citation: Scicchitano, P.; Tucci, M.; Ricci, G.; Gesualdo, M.; Carbonara, S.; Totaro, G.; Cecere, A.; Carbonara, R.; Cortese, F.; Loizzi, V.; et al. Vascular and Cardiac Prognostic Determinants in Patients with Gynecological Cancers: A Six-Year Follow-up Study. Appl. Sci. 2021, 11, 6091. https:// doi.org/10.3390/app11136091

Academic Editor: Qi-Huang Zheng

Received: 7 June 2021

Accepted: 26 June 2021

Published: 30 June 2021

Publisher's Note: MDPI stays neutral with regard to jurisdictional claims in published maps and institutional affiliations.

Copyright: (c) 2021 by the authors. Licensee MDPI, Basel, Switzerland. This article is an open access article distributed under the terms and conditions of the Creative Commons Attribution (CC BY) license (https:// creativecommons.org/licenses/by/ $4.0 /)$.
Abstract: Background: The aim of this study was to assess the role of cardiac and vascular parameters as all-cause mortality determinants in patients suffering from gynecological cancers. Methods: This was an observational, prospective, non-randomized, and non-controlled study. Forty-seven consecutive patients (mean age: $58 \pm 13$ years) were enrolled after cancer staging. All patients underwent evaluation of vascular (common carotid intima-media thickness (mean C-IMT), flowmediated dilation of the brachial artery (FMD), and antero-posterior diameter of the infrarenal abdominal aorta (APAO)) and cardiac function and morphology before cancer-related interventions. A 6-year follow-up was carried out to assess the overall survival of the whole population. Results: Twenty patients (42\%) died by the time of the 6-year follow-up. The brachial artery FMD values were higher in the survivors than the non-survivors $(9.71 \pm 3.53 \%$ vs. $6.13 \pm 2.62 \%, p<0.001)$, as well as the LVEF $(60.8 \pm 3.0 \%$ vs. $57.8 \pm 4.4 \%, p=0.009)$. There were no differences in the mean C-IMT, APAO, and other echocardiographic parameters. ROC curve analysis identified a baseline LVEF $<57 \%$ and FMD value $<5.8 \%$ as the best cut-offs. Kaplan-Meier evaluation showed that the LVEF, tricuspid annular plane systolic excursion, and FMD were the best predictors of all-cause mortality, although only the LVEF and FMD were confirmed in multivariate Cox regression analysis. Conclusions: The LVEF and brachial artery FMD are independent prognostic determinants in patients with gynecological cancers.

Keywords: gynecological cancer; cardiovascular risk profile; all-cause mortality; baseline evaluation; FMD; LVEF

\section{Introduction}

The worldwide incidence of cancer is steadily growing. In 2008, 12.7 million patients experienced cancer, and 7.6 million died [1]. Gynecological cancers represent about $11 \%$ of female cancers (nearly 183,000 cases in Italy in 2010) and are responsible for $9.4 \%$ deaths (6100 deaths / year in Italy) [2].

Early detection and advances in chemotherapy and targeted therapy have improved the prognoses of many types of cancer in terms of reduction in the mortality rate and an increase in the life expectancy $[3,4]$. Specifically, the adoption of dedicated chemotherapeutical protocols combined with improvement in surgical therapy can improve the overall 
survival of patients suffering from gynecological cancers [5-7]. Nevertheless, anti-tumor drugs may be associated with significant cardiovascular toxicity. About $30 \%$ of patients treated with chemotherapy develop abnormal heart functioning, which is classified as "relevant" in 15\% and "serious" (risk of fatal heart failure) in 1\% of cases [8]. Cardiovascular toxicity worsens the prognoses of these patients and limits the choice of the chemotherapeutical regimen, the dose intensity, and the potential anti-tumor efficacy of the therapy.

Parallel to that, there is growing evidence for possible crosstalk between the heart and cancer, which can deeply impact the prognoses of patients independent from the natural history of the neoplasm $[9,10]$. It has been recognized that heart failure can promote tumor growth by itself by means of the excretion of specific cardiac factors [11]. Such a relationship seems to be independent from the alterations in hemodynamics related to heart dysfunction [11].

The reciprocal linkage between the heart and cancer and the possible impact on patients' survival force evaluators to perform a comprehensive evaluation of patients suffering with neoplasms in order to detect early signs that might increase their risk for adverse events [9].

The literature offers scant data about the identification of specific cardiac determinants able to predict the prognoses of patients with cancers independent from the specific antiblastic treatment [12].

The aim of this study was to assess the impact of baseline cardiac and vascular parameters on the prognoses of women suffering with major gynecological cancers (uterine corpus, cervical, and ovarian).

\section{Materials and Methods}

This was an observational, prospective, non-randomized, and non-controlled study. From February 2015 to April 2016, we included 47 consecutive patients aged between 30 and 92 years (mean age $58 \pm 13$ years) after completing the diagnostic procedure and staging of the tumor.

The exclusion criteria were patients suffering from coagulopathies, systemic inflammatory disorders, and infective processes.

We gathered the main anthropometric, clinical, and laboratory data of the enrolled patients during the first visit at the outpatient clinic of the Gynecologic Oncology Unit at the University of Bari, Italy. The cardiovascular risk profile was assessed, including the medical history and cardiovascular risk factors such as hypertension, smoking, diabetes mellitus, dyslipidemia, a family history of ischemic heart disease, vascular disease, a history of arrhythmias, and stroke or transient ischemic attack.

At this stage, all patients were assessed for vascular and cardiac function and morphology. Specifically, common carotid intima-media thickness, flow- mediated dilation of the brachial artery, antero-posterior diameter of the infrarenal abdominal aorta, and echocardiographic evaluations were performed during first access to the researchers' attention $[13,14]$.

After completing the first outpatient medical examination, the patients were scheduled for surgery or antineoplastic chemotherapy for their gynecological malignancy according to standard national protocols.

All the patients underwent a 6-year follow-up by means of phone call investigation or examination of regional databases in order to assess the overall survival rate of the whole population.

This study was approved by the local ethics committee of the Policlinic of Bari, Italy. It was performed in accordance with the ethical standards laid out in the 1964 Declaration of Helsinki and its later amendments.

All of the patients gave their informed consent prior to their inclusion in the study. Details that might disclose the identity of the subjects have been omitted. 


\subsection{Flow-Mediated Dilation Measurement}

Patients underwent flow-mediated dilation evaluation. An ultrasound scanner with a linear probe from $7.5 \mathrm{MHz}$ to $10 \mathrm{MHz}$ was used. After fasting for at least 8-12 $\mathrm{h}$ and a rest period of about $10 \mathrm{~min}$, the brachial artery of the right arm was studied in longitudinal scans, with the probe placed over the elbow [13]. Measurement of the average diameter of the brachial artery at rest was performed. A sphygmomanometer was placed $3-5 \mathrm{~cm}$ below the bend of the elbow and inflated to a pressure of $50 \mathrm{mmHg}$ higher than the systolic blood pressure for $5 \mathrm{~min}$ [13]. After fast deflation, the flow-mediated dilation percentage was the maximum variation of the arterial diameter from baseline, calculated as the percentage difference between the maximum post-ischemic diameter and the average basal diameter. Our study protocol used an image analysis system certified by the CNR of Pisa (MVE II).

\subsection{Carotid Intima-Media Thickness Measurement}

The examination was performed with a high-frequency ultrasound probe $(7.5 \mathrm{MHz})$. Each patient was in a supine position, with the neck slightly hyperextended $\left(45^{\circ}\right)$ and laterally rotated in the opposite direction of the probe. The intima-media thickness was measured at the posterior wall of the common carotid artery at the end of diastole. The carotid intima-media thickness was obtained as the average from the left and right carotid intima-media thickness at three different carotid levels [13]: the proximal area, about $2 \mathrm{~cm}$ below the carotid bifurcation; the distal area, about $0.5 \mathrm{~cm}$ below the carotid bifurcation; and the intermediate zone. The same operator carried out all of the measurements in order to reduce bias.

\subsection{Infrarenal Abdominal Aorta Diameter Measurement}

An infrarenal abdominal aorta measurement was performed in each patient. The patient was supine. A high-resolution sector probe (frequency: $3.5 \mathrm{MHz}$ ) positioned $1 \mathrm{~cm}$ to the left of the navel was used. The infrarenal abdominal aorta diameter was defined as the maximum distance between the anterior and posterior abdominal aortic walls in a cross-section (short axis projection) [15]. The measurements were carried out at $0.5 \mathrm{~cm}$, $1 \mathrm{~cm}$, and $2 \mathrm{~cm}$ above the belly button. For better image quality, it was required for the patient to fast for at least six hours before the exam and possibly following a 2-day high fiber diet. The same operator performed each study.

\subsection{Evaluation of Cardiac Function}

The patients underwent two-dimensional color doppler transthoracic echocardiography with a Philips Sonos 5500 ultrasound system. Mono- and bidimensional evaluation of the cardiac chambers was performed according to international guidelines [14].

The LV diastolic function indexes were assessed by pulsed wave doppler and tissue doppler imaging. The left ventricle ejection fraction (LVEF) was calculated by means of the biplane Simpson method. The right ventricle systolic and diastolic function indexes (E/A ratio, E/E' ratio, and tricuspid annular plane systolic excursion (assessed by M-mode)) and left and right Tei indexes were also measured [16].

\subsection{Statistical Analysis}

The analyses were made using the Statistical Package for Social Science (SPSS) software, version 25.0 (SPSS Inc., Chicago, IL, USA). Data were expressed as the mean \pm standard deviation, and the categorical variables were expressed as numbers and percentages. The Kolmogorov-Smirnov test was applied in order to evaluate the distribution of the variables. Parameters with normal distribution were compared by means of a $t$-test for independent samples, while the Mann-Whitney test was adopted for parameters whose distributions were not normal.

We performed receiver operating characteristic (ROC) curve analysis in order to calculate the area under the curve (AUC) of the parameters, while the optimal cut-off values related to the survival rate were obtained by means of a Youden index. We calculated 
the Kaplan-Meier curves with the log-rank test. Uni- and multivariate analyses were performed with the Cox regression in order to evaluate the main predictors of all-cause mortality. The results were considered significant for $p<0.05$. The intra-observer variability of the ultrasound measurements was assessed by the intraclass correlation coefficient (good if $>0.80$ [17]). In particular, the evaluation of the carotid intima-media thickness showed excellent reproducibility (0.97), as well as the flow-mediated dilation and infrarenal abdominal aorta (intraclass correlation coefficient: 0.96 and 0.98 , respectively).

\section{Results}

Table 1 summarizes the clinical and laboratory characteristics of the study population. We divided patients into two groups: survivor and non-survivor patients at a long-term (6-year) follow-up.

Table 1. Baseline characteristics of the overall study population of surviving and non-surviving patients.

\begin{tabular}{|c|c|c|c|c|}
\hline Characteristics & All Patients & Survivors & Non-Survivors & $p$-Values \\
\hline Total number of patients (n, \%) & $47(100)$ & $27(100)$ & $20(100)$ & \\
\hline Mean age (years) & $58.6 \pm 13.1$ & $55.3 \pm 11.3$ & $62.9 \pm 14.4$ & 0.048 \\
\hline Hypertension (n, \%) & $21(44.7)$ & $13(48.1)$ & $8(40)$ & 0.59 \\
\hline Diabetes $(n, \%)$ & $2(4.3)$ & $1(3.7)$ & $1(5)$ & 0.83 \\
\hline Dyslipidemia (n, \%) & $6(12.8)$ & $5(18.5)$ & $1(5)$ & 0.18 \\
\hline Ischemic heart disease $(n, \%)$ & $2(4.3)$ & $1(3.7)$ & $1(5)$ & 0.83 \\
\hline Peripheral artery disease $(n, \%)$ & $2(4.3)$ & $0(0)$ & $2(10)$ & 0.10 \\
\hline Previous stroke or TIA $(\mathrm{n}, \%)$ & $2(4.3)$ & $0(0)$ & $2(10)$ & 0.10 \\
\hline Family history CVD (n, \%) & $19(40.4)$ & $13(48.1)$ & $6(30)$ & 0.22 \\
\hline Smoking $(\mathrm{n}, \%)$ & $3(6.4)$ & $1(3.7)$ & $2(10)$ & 0.39 \\
\hline Chemotherapy (n, \%) & $32(68.1)$ & $15(55.5)$ & $17(85)$ & 0.03 \\
\hline \multicolumn{5}{|l|}{ Type of chemotherapy } \\
\hline Doxorubicin alone (n, \%) & $1(2.1)$ & $0(0)$ & $1(5)$ & 0.25 \\
\hline Paclitaxel alone (n, \%) & $1(2.1)$ & $1(3.7)$ & $0(0)$ & 0.39 \\
\hline Carboplatin + paclitaxel $(\mathrm{n}, \%)$ & $21(44.7)$ & $13(48.1)$ & $8(40)$ & 0.59 \\
\hline $\begin{array}{l}\text { Carboplatin + paclitaxel }+ \\
\text { bevacizumab }(n, \%)\end{array}$ & $9(19.1)$ & $7(25.9)$ & $2(10)$ & 0.17 \\
\hline Surgical intervention $(\mathrm{n}, \%)$ & $18(38.3)$ & $14(51.8)$ & $4(20)$ & 0.03 \\
\hline \multicolumn{5}{|l|}{ Type of cancer } \\
\hline Ovarian cancer diagnosis (n, \%) & $25(53.2)$ & $14(51.8)$ & $11(55)$ & \\
\hline Endometrial cancer diagnosis (n, \%) & $13(27.7)$ & $8(29.6)$ & $5(25)$ & \\
\hline Uterine cervix cancer diagnosis (n, \%) & $7(14.9)$ & $5(18.5)$ & $2(10)$ & \\
\hline Vulvar cancer diagnosis $(n, \%)$ & $2(4.3)$ & $0(0)$ & $2(10)$ & \\
\hline Follow-up duration (days) & $1364.3 \pm 676.1$ & $1870.5 \pm 120.1$ & $680.9 \pm 480.1$ & $<0.0001$ \\
\hline \multicolumn{5}{|l|}{ Laboratory evaluation } \\
\hline $\mathrm{RBC}\left(\times 10^{6} / \mathrm{mm}^{3}\right)$ & $4.21 \pm 0.37$ & $4.25 \pm 0.32$ & $4.15 \pm 0.43$ & 0.39 \\
\hline $\mathrm{WBC}\left(\times 10^{3} / \mathrm{mm}^{3}\right)$ & $6.39 \pm 2.24$ & $6.58 \pm 2.31$ & $6.14 \pm 2.18$ & 0.51 \\
\hline $\mathrm{Hb}(\mathrm{g} / \mathrm{dL})$ & $12.0 \pm 1.2$ & $11.9 \pm 1.2$ & $12.1 \pm 1.2$ & 0.61 \\
\hline $\mathrm{HCT}(\%)$ & $36.2 \pm 3.4$ & $35.7 \pm 2.9$ & $37.0 \pm 3.8$ & 0.20 \\
\hline $\mathrm{MCH}(\mu \mathrm{g} / \mathrm{mL})$ & $28.6 \pm 2.7$ & $28.0 \pm 2.6$ & $29.5 \pm 2.6$ & 0.06 \\
\hline $\mathrm{MCHC}(\mu \mathrm{g} / \mathrm{mL})$ & $33.2 \pm 1.5$ & $33.4 \pm 1.4$ & $32.9 \pm 1.6$ & 0.32 \\
\hline $\operatorname{MCV}(\mathrm{fL})$ & $86.4 \pm 6.8$ & $84.0 \pm 5.9$ & $89.5 \pm 6.9$ & 0.006 \\
\hline $\operatorname{PLT}\left(\times 10^{3} / \mathrm{mm}^{3}\right)$ & $268.1 \pm 92.2$ & $253.6 \pm 79.1$ & $287.5 \pm 106.4$ & 0.22 \\
\hline Total cholesterol (mg/dL) & $179.2 \pm 28.4$ & $179.1 \pm 31.4$ & $179.3 \pm 24.6$ & 0.98 \\
\hline $\mathrm{TG}(\mathrm{mg} / \mathrm{dL})$ & $109.4 \pm 28.4$ & $109.6 \pm 31.1$ & $109.0 \pm 26.4$ & 0.94 \\
\hline HDL-C (mg/dL) & $48.9 \pm 8.8$ & $49.0 \pm 7.7$ & $48.7 \pm 10.4$ & 0.93 \\
\hline LDL-C (mg/dL) & $108.5 \pm 29.1$ & $108.2 \pm 30.7$ & $108.8 \pm 27.6$ & 0.95 \\
\hline Fasting glycemia (mg/dL) & $96.9 \pm 27.1$ & $97.5 \pm 32.3$ & $96.2 \pm 18.7$ & 0.88 \\
\hline Creatinine $(\mathrm{mg} / \mathrm{dL})$ & $0.71 \pm 0.21$ & $0.71 \pm 0.18$ & $0.71 \pm 0.24$ & 0.97 \\
\hline
\end{tabular}

Numbers are expressed as the mean \pm standard deviation or number and percentages. Abbreviations: CVD: cardiovascular diseases; Hb: hemoglobin; HCT: hematocrit; HDL-C: high-density lipoprotein cholesterol; LDL-C: low-density lipoprotein cholesterol; MCH: mean corpuscular hemoglobin; MCHC: mean corpuscular hemoglobin concentration; MCV: mean corpuscular volume; PLT: platelets; RBC: red blood cells; TG: triglycerides; TIA: transient ischemic attack; WBC: white blood cells. 
Twenty patients $(42 \%)$ died by the time of the 6-year follow-up. Both groups were similar according to the common cardiovascular risk factors. The non-survivors were older than the survivors, underwent chemotherapy more often, and had less surgical intervention compared with the survivors. The mean duration of the follow-up period was longer in the survivors than the non-survivors (1870.5 \pm 120.1 days vs. $680.9 \pm 480.1$ days, $p<0.0001$ ).

Table 2 includes the comparisons between the two groups according to the echocardiographic and vascular parameters. The values of the brachial artery FMD were better in the survivors than the non-survivors $(9.71 \pm 3.53 \%$ vs. $6.13 \pm 2.62 \%, p<0.001)$, while no differences were found in terms of the mean C-IMT and APAO values between the groups ( $p=0.48$ and $\mathrm{p}=0.45$, respectively). According to the echocardiographic parameters, the LVEF was higher in the survivors than the non-survivors $(60.8 \pm 3.0 \%$ vs. $57.8 \pm 4.4 \%$, $p=0.009$ ). The non-survivors showed increased end-diastolic and end-systolic diameters of the left ventricle as well as the aortic root diameter. A higher left E/A ratio was also detected. There were no differences according to tissue doppler imaging analysis. In particular, both the left and right TEI indexes were similar between the two groups.

Indeed, the adoption of Kaplan-Meier evaluation allowed us to observe a significant increase in the all-cause mortality rate when the LVEF, TAPSE, and FMD were lower than their calculated cut-offs (Figure 1).

Table 2. Echocardiographic and vascular parameters showing comparisons between surviving and non-surviving patients.

\begin{tabular}{|c|c|c|c|c|}
\hline Characteristics & All Patients $(n=47)$ & Survivors $(n=27)$ & Non-Survivors $(n=20)$ & $p$-Values \\
\hline FMD (\%) & $8.2 \pm 3.6$ & $9.71 \pm 3.53$ & $6.13 \pm 2.62$ & $<0.001$ \\
\hline Mean C-IMT (mm) & $0.69 \pm 0.15$ & $0.68 \pm 0.13$ & $0.71 \pm 0.17$ & 0.48 \\
\hline $\mathrm{APAO}(\mathrm{cm})$ & $1.58 \pm 0.27$ & $1.61 \pm 0.29$ & $1.54 \pm 0.23$ & 0.45 \\
\hline $\operatorname{LV} \operatorname{EDD}(\mathrm{mm})$ & $43.0 \pm 8.9$ & $40.76 \pm 3.71$ & $46.07 \pm 12.56$ & 0.043 \\
\hline $\operatorname{LVESD}(\mathrm{mm})$ & $28.2 \pm 5.0$ & $26.30 \pm 4.03$ & $30.79 \pm 5.02$ & 0.0014 \\
\hline IVS (mm) & $11.1 \pm 1.8$ & $10.9 \pm 1.7$ & $11.3 \pm 1.8$ & 0.42 \\
\hline LA APD (mm) & $36.7 \pm 5.2$ & $36.0 \pm 5.8$ & $37.7 \pm 4.3$ & 0.30 \\
\hline AoR $(\mathrm{mm})$ & $29.5 \pm 3.2$ & $28.6 \pm 3.0$ & $30.7 \pm 3.2$ & 0.03 \\
\hline $\operatorname{LVEF}(\%)$ & $59.5 \pm 3.9$ & $60.8 \pm 3.0$ & $57.8 \pm 4.4$ & 0.009 \\
\hline Left $E(\mathrm{~cm} / \mathrm{s})$ & $67.96 \pm 22.29$ & $61.41 \pm 13.68$ & $76.8 \pm 28.36$ & 0.02 \\
\hline Left A $(\mathrm{cm} / \mathrm{s})$ & $76.04 \pm 20.99$ & $79.98 \pm 18.98$ & $70.71 \pm 22.84$ & 0.14 \\
\hline Left E/A ratio & $1.00 \pm 0.62$ & $0.79 \pm 0.19$ & $1.29 \pm 0.85$ & 0.0048 \\
\hline Left $\mathrm{e}^{\prime}(\mathrm{cm} / \mathrm{s})$ & $7.39 \pm 2.32$ & $7.24 \pm 2.75$ & $7.60 \pm 1.64$ & 0.60 \\
\hline Left $\mathrm{a}^{\prime}(\mathrm{cm} / \mathrm{s})$ & $9.37 \pm 3.14$ & $9.37 \pm 2.41$ & $9.38 \pm 3.98$ & 0.99 \\
\hline Left s' $(\mathrm{cm} / \mathrm{s})$ & $7.11 \pm 1.75$ & $7.25 \pm 1.68$ & $6.92 \pm 1.87$ & 0.53 \\
\hline Left IVRT (ms) & $71.49 \pm 19.75$ & $71.48 \pm 20.13$ & $71.50 \pm 10.74$ & 0.99 \\
\hline Left ET(ms) & $282.77 \pm 39.31$ & $284.07 \pm 34.67$ & $281.00 \pm 45.73$ & 0.79 \\
\hline Left IVCT (ms) & $60.32 \pm 17.52$ & $57.78 \pm 16.25$ & $63.75 \pm 18.98$ & 0.25 \\
\hline Left Tei index & $0.47 \pm 0.12$ & $0.46 \pm 0.12$ & $0.49 \pm 0.13$ & 0.45 \\
\hline Left $\mathrm{E} / \mathrm{e}^{\prime}$ ratio & $10.05 \pm 4.73$ & $9.55 \pm 4.11$ & $10.72 \pm 5.50$ & 0.41 \\
\hline TAPSE (mm) & $22.7 \pm 4.1$ & $23.1 \pm 4.1$ & $22.3 \pm 4.1$ & 0.52 \\
\hline Right E (cm/s) & $50.26 \pm 10.73$ & $50.10 \pm 10.21$ & $50.47 \pm 11.66$ & 0.91 \\
\hline Right A $(\mathrm{cm} / \mathrm{s})$ & $51.40 \pm 14.33$ & $52.60 \pm 12.37$ & $49.78 \pm 16.83$ & 0.51 \\
\hline Right E/A ratio & $1.04 \pm 0.36$ & $0.99 \pm 0.27$ & $1.12 \pm 0.45$ & 0.23 \\
\hline Right $\mathrm{e}^{\prime}(\mathrm{cm} / \mathrm{s})$ & $11.56 \pm 3.71$ & $10.98 \pm 2.90$ & $12.36 \pm 4.55$ & 0.21 \\
\hline Right a' $(\mathrm{cm} / \mathrm{s})$ & $15.96 \pm 5.00$ & $16.25 \pm 4.50$ & $15.57 \pm 5.69$ & 0.65 \\
\hline Right $\mathrm{s}^{\prime}(\mathrm{cm} / \mathrm{s})$ & $12.91 \pm 3.23$ & $12.94 \pm 3.13$ & $12.88 \pm 3.45$ & 0.95 \\
\hline Right IVRT (ms) & $63.08 \pm 18.75$ & $62.59 \pm 21.05$ & $63.75 \pm 15.63$ & 0.84 \\
\hline Right ET (ms) & $284.04 \pm 46.28$ & $281.11 \pm 42.55$ & $288.00 \pm 51.77$ & 0.62 \\
\hline Right IVCT (ms) & $57.77 \pm 15.94$ & $56.30 \pm 16.67$ & $59.75 \pm 15.08$ & 0.47 \\
\hline Right Tei index & $0.44 \pm 0.12$ & $0.43 \pm 0.14$ & $0.44 \pm 0.10$ & 0.85 \\
\hline Right E/e' ratio & $4.65 \pm 1.50$ & $4.84 \pm 1.58$ & $4.40 \pm 1.38$ & 0.32 \\
\hline
\end{tabular}

Numbers are expressed as the mean \pm standard deviation. Abbreviations: AoR: aortic root diameter; APAO: antero-posterior diameter of the infrarenal abdominal aorta; FMD: flow-mediated vasodilatation; ET: ejection time; IVCT: isovolumic contraction time; IVRT: isovolumic relaxation time; IVS: interventricular septum; LA-APD: left atrial-antero-posterior diameter; LVEDD: left ventricle end-diastolic diameter; LVEF: left ventricle ejection fraction; LVESD: left ventricle end-systolic diameter; mean C-IMT: mean common carotid intima-media thickness; TAPSE: tricuspid annular plane systolic excursion. 

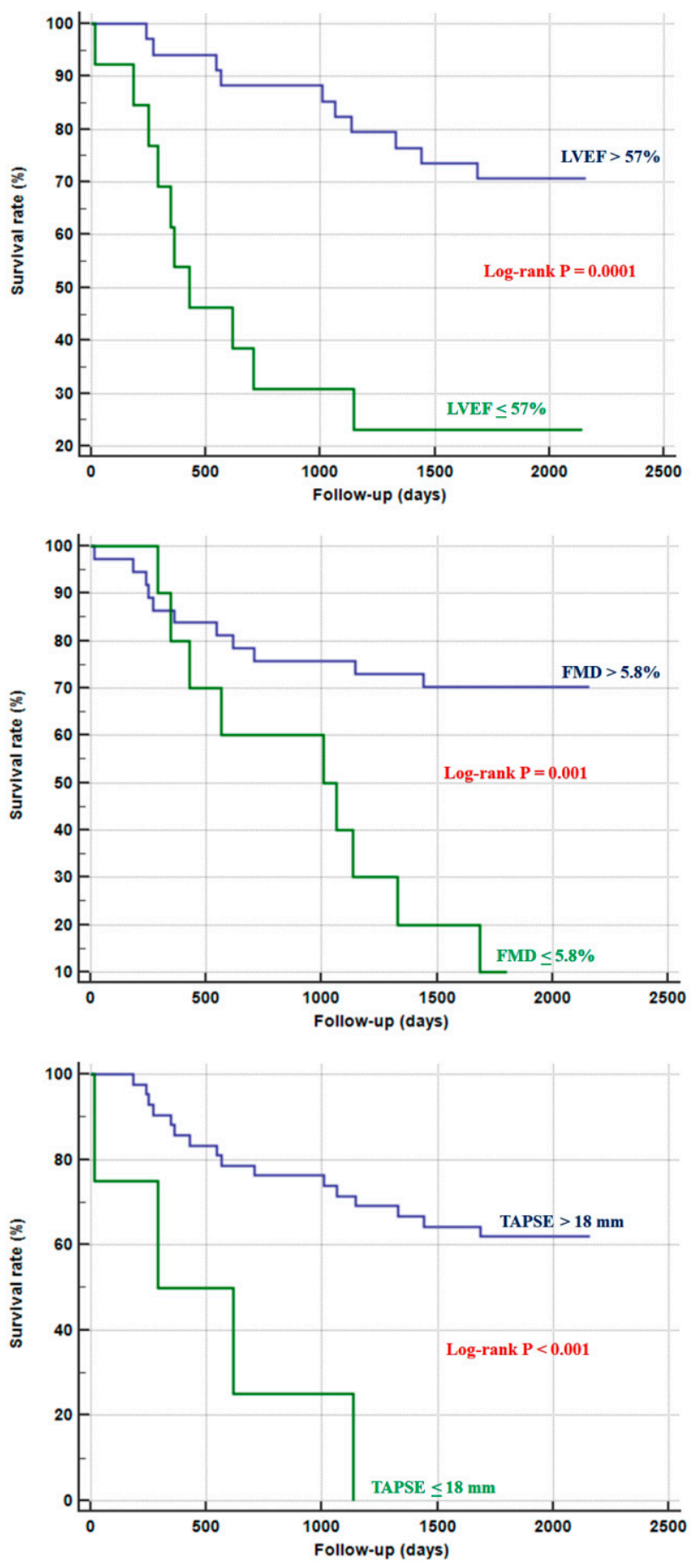

Figure 1. Survival curves for all-cause mortality according to the vascular and echocardiographic parameters dichotomized by their optimal cut-off. FMD: flow-mediated vasodilatation of the branchial artery; LVEF: left ventricle ejection fraction; TAPSE: tricuspid annular plane systolic excursion.

ROC curve analysis was used in order to identify the cut-offs of the echocardiographic and vascular parameters that were able to predict mortality. Table 3 gathers the main findings from the analysis, where the baseline LVEF $\leq 57 \%$ and baseline FMD value $\leq 5.8 \%$ represent the significant cut-offs retrieved from the analysis. 
Table 3. Echocardiographic and vascular predictors of all-cause mortality.

\begin{tabular}{|c|c|c|c|c|c|c|c|}
\hline Parameter & $\begin{array}{l}\text { Survivors } \\
(\mathrm{n}=27)\end{array}$ & $\begin{array}{l}\text { Non-Survivors } \\
\quad(n=20)\end{array}$ & Cut-off & $\begin{array}{c}\text { Sensibility } \\
(\%)\end{array}$ & $\begin{array}{c}\text { Specificity } \\
(\%)\end{array}$ & AUC & $p$ \\
\hline LVEF (\%) & $60.81 \pm 3.03$ & $57.85 \pm 4.45$ & $\leq 57$ & 50 & 88.9 & 0.740 & 0.0014 \\
\hline Left E/A ratio & $0.79 \pm 0.19$ & $1.29 \pm 0.85$ & $>1.16$ & 45 & 96.3 & 0.661 & 0.07 \\
\hline Left $\mathrm{E} / \mathrm{e}^{\prime}$ ratio & $9.55 \pm 4.11$ & $10.72 \pm 5.50$ & $>7.87$ & 70 & 51.8 & 0.589 & 029 \\
\hline Left TEI index & $0.46 \pm 0.12$ & $0.49 \pm 0.13$ & $>0.42$ & 65 & 55.6 & 0.562 & 0.47 \\
\hline TAPSE (mm) & $23.08 \pm 4.11$ & $22.29 \pm 4.12$ & $\leq 18$ & 20 & 96.3 & 0.534 & 0.69 \\
\hline Right E/A ratio & $0.99 \pm 0.27$ & $1.12 \pm 0.45$ & $>0.91$ & 60 & 66.7 & 0.561 & 0.50 \\
\hline Right E/e' ratio & $4.84 \pm 1.58$ & $4.40 \pm 1.38$ & $\leq 4.52$ & 70 & 59.3 & 0.600 & 0.24 \\
\hline Right TEI index & $0.43 \pm 0.14$ & $0.44 \pm 0.10$ & $>0.44$ & 55 & 63 & 0.547 & 0.58 \\
\hline FMD $(\%)$ & $9.71 \pm 3.53$ & $6.13 \pm 2.62$ & $\leq 5.8$ & 45 & 96.3 & 0.756 & 0.0003 \\
\hline $\mathrm{APAO}(\mathrm{mm})$ & $1.61 \pm 0.29$ & $1.54 \pm 0.23$ & $\overline{\leq} 1.59$ & 70 & 55.6 & 0.570 & 0.40 \\
\hline Mean C-IMT (mm) & $0.68 \pm 0.13$ & $0.71 \pm 0.17$ & $>0.83$ & 25 & 92.6 & 0.533 & 0.70 \\
\hline
\end{tabular}

Abbreviations: APAO: antero-posterior diameter of the infrarenal abdominal aorta; AUC: area under the curve FMD: flow-mediated vasodilatation; LVEF: left ventricle ejection fraction; mean C-IMT: mean common carotid intima-media thickness; TAPSE: tricuspid annular plane systolic excursion.

Nevertheless, in the multivariate Cox regression analysis, only the LVEF, FMD, and E/A ratio demonstrated that they acted as independent predictors of all-cause mortality in patients suffering from gynecological cancers (Table 4).

Table 4. Univariate and multivariate Cox regression analysis with independent all-cause mortality predictors.

\begin{tabular}{cccccc}
\hline & \multicolumn{2}{c}{ Univariate Analysis } & \multicolumn{2}{c}{ Multivariate Analysis } \\
\hline Parameter & $\boldsymbol{\beta} \pm \mathbf{S E}$ & $\boldsymbol{p}$-Value & $\boldsymbol{\beta} \pm \mathbf{S E}$ & Wald & $\boldsymbol{p}$-Value \\
\hline LVEF & $-0.228 \pm 0.068$ & 0.0009 & $-0.225 \pm 0.089$ & 6.379 & 0.0115 \\
FMD & $-0.213 \pm 0.073$ & 0.0037 & $-0.249 \pm 0.106$ & 5.497 & 0.0190 \\
Left E/A ratio & $1.123 \pm 0.299$ & 0.0002 & $0.714 \pm 0.353$ & & \\
TAPSE & $-0.061 \pm 0.063$ & 0.3302 & & \\
Age & $0.044 \pm 0.018$ & 0.0163 & & \\
Peripheral artery diseases & $1.703 \pm 0.779$ & 0.0288 & & \\
Chemotherapy & $-1.212 \pm 0.627$ & 0.0532 & & \\
Surgical intervention & $1.088 \pm 0.560$ & 0.0522 & & \\
\hline
\end{tabular}

Abbreviations: FMD: flow-mediated vasodilatation; LVEF: left ventricle ejection fraction; SE: standard error.

\section{Discussion}

The present study demonstrated that baseline evaluation of the cardiac and vascular parameters might improve the evaluation of the prognoses of women suffering from major gynecological cancers (uterine corpus, cervical, and ovarian). In particular, the endothelial function (brachial artery FMD $\leq 5.8 \%$ ) and left ventricle contractility (LVEF $\leq 57 \%$ ) demonstrated that they were independently related to the mortality of patients with gynecological cancers.

The prognoses of patients suffering with cancer is worse despite the improvements in therapy and advances in early diagnosis [1-3]. The rare prevalence of gynecological cancers and the difficulties in early diagnosis are responsible for the poor survival rate of patients [18].

The identification of early signs of poor prognoses in cancer patients-and gynecological ones in particular-is a fundamental step when evaluating such individuals in order to better stratify their risk of adverse events beyond the evolution of the cancer itself.

Echocardiography and vascular ultrasound examinations may represent good tools to be included in the general evaluation of patients with cancer before chemo- or radiotherapy and surgery in order to better evaluate their baseline cardiovascular risk and intensify treatments for preventing adverse events.

The prognostic values of the LVEF in cancer patients who underwent chemotherapy were established $[19,20]$. All forms of chemotherapy are known to promote cardiac dysfunction in a reversible or irreversible manner [14]. Even patients without significant cardiovascular risk factors may experience cardiac toxicity from chemo- or radiotherapy upon a long-term follow-up [21-23]. The mechanisms by which heart can be deeply affected 
by these drugs are different: apoptosis of cardiomyocytes, deregulation of mitochondrial biochemical pathways, and increasing the production of oxygen free radicals [24,25].

Indeed, no study evaluated the impact of baseline evaluation of the LVEF on the prognoses of patients with cancer. Our study is the first one dealing with the long-term (6 years) impact of left ventricle function on the prognoses of patients with gynecological cancers. We demonstrated that an LVEF $\leq 57 \%$ was able to detect patients' mortality with a sensibility of $50 \%$, specificity of $88.9 \%$, and AUC of 0.740 . Multivariate Cox regression analysis confirmed the independent role of the LVEF as an all-cause mortality predictor. Parallel to that, right ventricle function, evaluated by means of TAPSE, seemed to be able to predict mortality in gynecological cancers.

The consequences of this study are mainly related to the additional need for a comprehensive baseline evaluation of patients with gynecological cancers by means of echocardiography. Abu-Khalaf et al. [26] demonstrated the cost-effectiveness of baseline evaluation of left ventricle function in patients with cancer who would undergo chemotherapy. The echocardiographic screening allows for the opportunity to detect cardiac impairment before the beginning of the anti-proliferative therapy and, in parallel, to ideally identify those individuals with apparently normal LVEFs, but who are prone to suffer reduced survival in the long term after treatment of their cancer. A retrospective study on 482 patients with breast cancer who underwent LVEF evaluation before anthracycline-based chemotherapy administration demonstrated the change in chemotherapy regimen in relation to their baseline LVEF values [27]. Truong et al. [28] pointed out that most patients with breast cancer who developed cardiac events did not undergo baseline evaluation of their LVEFs before chemotherapy administration. Nevertheless, a recent meta-analysis from O'Brien et al. [29] reduced the value of the baseline evaluation of echocardiography and the LVEF in the management of patients with breast cancer, although further structured trials should be planned.

Endothelial dysfunction is related to adverse cardiovascular event mortality [30,31]. It is mainly related to cardiovascular risk factors and can be considered an early sign of atherosclerotic disease [13]. Patients with cancer may demonstrate endothelial dysfunction as the main cause of chemo- or radiotherapy, as these effectively inhibit nitric oxide production, promote endothelial cell proliferation, and increase the release of chemokines and adhesion molecules [32-34]. Nevertheless, the literature is scant in relation to data about the impact of baseline endothelial function evaluation on the prognoses of patients with cancer and gynecological cancers in particular. Most studies focused on the impact of chemo- and radiotherapy on endothelial function in patients with cancer [35-37]. Our study demonstrated that the baseline evaluation of endothelial function in patients with gynecological cancers is an independent predictor of mortality. In particular, the brachial artery's FMD being $\leq 5.8 \%$ showed a sensibility of $45 \%$, specificity of 96.3 , and AUC of 0.756 (Table 3). The reason for the correlation between endothelial function and mortality in patients with cancer is still a matter of debate. Endothelial dysfunction is related to heart failure [38], and thus lower FMD values might predispose a person to cardiac dysfunction after chemotherapy. Alterations in the endothelium can promote coronary and cerebrovascular diseases which, in turn, might negatively impact the prognoses of the patients $[39,40]$.

Finally, deregulation in the autocrine and paracrine function of the endothelial layer might be involved in the occurrence of neoangiogenesis within carcinomatous mass and the development of metastases [41]. Taken all together, these results can largely explain the influence of endothelial function on the prognoses of patients with cancer, namely those with gynecological cancers. Further studies are needed in order to validate such hypotheses.

\section{Conclusions}

The LVEF and brachial artery FMD are independent prognostic determinants in patients with gynecological cancer. Baseline evaluation of the cardiac and vascular function 
in patients with cancer-gynecological neoplasms in particular-should be carefully considered in order to better stratify the overall risk for these patients.

Author Contributions: Conceptualization, P.S., M.T., V.L., G.C., E.C. and M.M.C.; methodology, P.S., M.T., V.L., G.C., E.C. and M.M.C.; validation, P.S., M.T., G.R., M.G., S.C., G.T., V.L., G.C., E.C. and M.M.C.; formal analysis, P.S., M.T., A.C., R.C., F.C., V.L., G.C., E.C. and M.M.C.; investigation, P.S., M.T., V.L., G.C., E.C. and M.M.C.; data curation, P.S., M.T., V.L., G.C., E.C. and M.M.C.; writingoriginal draft preparation, P.S., M.T., V.L., G.C., G.R., M.G., S.C., G.T., E.C. and M.M.C.; writingreview and editing, P.S., M.T., A.C., R.C., F.C., V.L., G.C., E.C. and M.M.C.; visualization, G.R., M.G., A.C., R.C., F.C., S.C. and G.T.; supervision, G.R., M.G., A.C., R.C., F.C., S.C. and G.T.; project administration, P.S., M.T., V.L., G.C., E.C. and M.M.C. All authors have read and agreed to the published version of the manuscript.

Funding: This research received no external funding.

Institutional Review Board Statement: This study was conducted according to the guidelines of the Declaration of Helsinki and approved by the Ethics Committee of Policlinic of Bari in Bari, Italy.

Informed Consent Statement: Informed consent was obtained from all subjects involved in the study. Written informed consent has been obtained from the patients to publish this paper.

Data Availability Statement: Data will be available on request by contacting the corresponding author.

Conflicts of Interest: The authors declare no conflict of interest.

\section{References}

1. Jemal, A.; Bray, F.; Center, M.M.; Ferlay, J.; Ward, E.; Forman, D. Global cancer statistics. CA Cancer J. Clin. 2011, 61, 69-90. [CrossRef]

2. AIOM AIRTUM. I Numeri del Cancro in Italia. 2014. Available online: www.registri-tumori.it/PDF/AIOM2014/I_numeri_del_ cancro_2014.pdf (accessed on 16 January 2020).

3. Sant, M.; Allemani, C.; Santaquilani, M.; Knijn, A.; Marchesi, F.; Capocaccia, R.; EUROCARE Working Group. Survival of cancer patients diagnosed in 1995-1999. Results and commentary. Eur. J. Cancer 2009, 45, 931-991. [CrossRef]

4. Oeffinger, K.C.; Mertens, A.C.; Sklar, C.A.; Kawashima, T.; Hudson, M.M.; Meadows, A.T.; Friedman, D.L.; Marina, N.; Hobbie, W.; Kadan-Lottick, N.S.; et al. Chronic health conditions in adult survivors of childhood cancer. N. Engl. J. Med. 2006, 355, 1572-1582. [CrossRef]

5. Huang, H.; Feng, Y.L.; Wan, T.; Zhang, Y.N.; Cao, X.P.; Huang, Y.W.; Xiong, Y.; Huang, X.; Zheng, M.; Li, Y.F.; et al. Effectiveness of Sequential Chemoradiation vs Concurrent Chemoradiation or Radiation Alone in Adjuvant Treatment After Hysterectomy for Cervical Cancer: The STARS Phase 3 Randomized Clinical Trial. JAMA Oncol. 2021, 7, 361-369. [CrossRef]

6. Wang, B.; Tan, Y.; Yang, X.; Man, X. Survival outcomes of neoadjuvant chemotherapy-related strategies compared with concurrent chemoradiotherapy for locally advanced cervical cancer: A meta-analysis of randomized controlled trials. Arch. Gynecol. Obstet. 2021. [CrossRef]

7. Bisch, S.P.; Jago, C.A.; Kalogera, E.; Ganshorn, H.; Meyer, L.A.; Ramirez, P.T.; Dowdy, S.C.; Nelson, G. Outcomes of enhanced recovery after surgery (ERAS) in gynecologic oncology-A systematic review and meta-analysis. Gynecol. Oncol. 2021, 161, 46-55. [CrossRef]

8. Botteri, E.; Iodice, S.; Maisonneuve, P.; Alfieri, M.; Burzoni, N.; Manghi, L.; Martinetti, M.; Montanari, B.; Albertazzi, E.; Bazolli, B.; et al. Case mix at the European Institute of Oncology: First report of the Tumour Registry, 2000-2002. Ecancermedicalscience 2009, 3, 149. [CrossRef]

9. Brancaccio, M.; Pirozzi, F.; Hirsch, E.; Ghigo, A. Mechanisms underlying the cross-talk between heart and cancer. J. Physiol. 2020, 598, 3015-3027. [CrossRef]

10. Moslehi, J.; Zhang, Q.; Moore, K.J. Crosstalk Between the Heart and Cancer: Beyond Drug Toxicity. Circulation 2020, 142, 684-687. [CrossRef]

11. Meijers, W.C.; Maglione, M.; Bakker, S.J.L.; Oberhuber, R.; Kieneker, L.M.; de Jong, S.; Haubner, B.J.; Nagengast, W.B.; Lyon, A.R.; van der Vegt, B.; et al. Heart Failure Stimulates Tumor Growth by Circulating Factors. Circulation 2018, 138, 678-691. [CrossRef]

12. Rhea, I.B.; Uppuluri, S.; Sawada, S.; Schneider, B.P.; Feigenbaum, H. Incremental prognostic value of echocardiographic strain and its association with mortality in cancer patients. J. Am. Soc. Echocardiogr. 2015, 28, 667-673. [CrossRef]

13. Ciccone, M.M.; Bilianou, E.; Balbarini, A.; Gesualdo, M.; Ghiadoni, L.; Metra, M.; Palmiero, P.; Pedrinelli, R.; Salvetti, M.; Scicchitano, P.; et al. Task force on: 'Early markers of atherosclerosis: Influence of age and sex'. J. Cardiovasc. Med. 2013, 14, 757-766. [CrossRef] 
14. Plana, J.C.; Galderisi, M.; Barac, A.; Ewer, M.S.; Ky, B.; Scherrer-Crosbie, M.; Ganame, J.; Sebag, I.A.; Agler, D.A.; Badano, L.P.; et al. Expert consensus for multimodality imaging evaluation of adult patients during and after cancer therapy: A report from the American Society of Echocardiography and the European Association of Cardiovascular Imaging. Eur. Heart J. Cardiovasc. Imaging 2014, 15, 1063-1093. [CrossRef]

15. Ciccone, M.M.; Favale, S.; Bhuva, A.; Scicchitano, P.; Caragnano, V.; Lavopa, C.; De Pergola, G.; Loverro, G. Antero-posterior diameter of the infrarenal abdominal aorta is higher in women with polycystic ovary syndrome. Vasc. Health Risk Manag. 2009, 5, 561-566.

16. Lang, R.M.; Badano, L.P.; Mor-Avi, V.; Afilalo, J.; Armstrong, A.; Ernande, L.; Flachskampf, F.A.; Foster, E.; Goldstein, S.A.; Kuznetsova, T.; et al. Recommendations for cardiac chamber quantification by echocardiography in adults: An update from the American Society of Echocardiography and the European Association of Cardiovascular Imaging. Eur. Heart J. Cardiovasc. Imaging 2015, 16, 233-271. [CrossRef]

17. Fleiss, J.L.; Cohen, J. The equivalence of weighted kappa and the intraclass correlation coefficient as measures of reliability. Educ. Psychol. Meas. 1973, 33, 613-619. [CrossRef]

18. Di Fiore, R.; Suleiman, S.; Ellul, B.; O’Toole, S.A.; Savona-Ventura, C.; Felix, A.; Napolioni, V.; Conlon, N.T.; Kahramanoglu, I.; Azzopardi, M.J.; et al. GYNOCARE Update: Modern Strategies to Improve Diagnosis and Treatment of Rare Gynecologic Tumors-Current Challenges and Future Directions. Cancers 2021, 13, 493. [CrossRef]

19. Kim, E.K.; Cho, J.; Kim, J.Y.; Chang, S.A.; Park, S.J.; Choi, J.O.; Lee, S.C.; Ahn, J.S.; Park, S.W.; Im, Y.H.; et al. Early Decline in Left Ventricular Ejection Fraction Can Predict Trastuzumab-Related Cardiotoxicity in Patients with Breast Cancer: A Study Using 13 Years of Registry Data. Cancer Res. Treat. Off. J. Korean Cancer Assoc. 2019, 51, 727-736. [CrossRef]

20. López-Sendón, J.; Álvarez-Ortega, C.; Zamora Auñon, P.; Buño Soto, A.; Lyon, A.R.; Farmakis, D.; Cardinale, D.; Canales Albendea, M.; Feliu Batlle, J.; Rodríguez Rodríguez, I.; et al. Classification, prevalence, and outcomes of anticancer therapy-induced cardiotoxicity: The CARDIOTOX registry. Eur. Heart J. 2020, 41, 1720-1729. [CrossRef]

21. Arbuck, S.G.; Strauss, H.; Rowinsky, E.; Christian, M.; Suffness, M.; Adams, J.; Oakes, M.; McGuire, W.; Reed, E.; Gibbs, H.; et al. A reassessment of cardiac toxicity associated with Taxol. J. Natl. Cancer Inst. Monogr. 1993, 15, 117-130.

22. Rowinsky, E.K.; McGuire, W.P.; Guarnieri, T.; Fisherman, J.S.; Christian, M.C.; Donehower, R.C. Cardiac disturbances during the administration of taxol. J. Clin. Oncol. 1991, 9, 1704-1712. [CrossRef]

23. Liu, B.J.; Li, X.P.; Wang, J.L.; Wu, Y.; Wei, L.H. Analysis of cardiotoxicity of chemotherapy in 30 cases with gynecological cancer. Zhonghua Fu Chan Ke Za Zhi 2011, 46, 884-887.

24. Cheng, C.F.; Juan, S.H.; Chen, J.J.; Chao, Y.C.; Chen, H.H.; Lian, W.S.; Lu, C.Y.; Chang, C.I.; Chiu, T.H.; Lin, H. Pravastatin attenuates carboplatin-induced cardiotoxicity via inhibition of oxidative stress associated apoptosis. Apoptosis 2008, 13, 883-894. [CrossRef]

25. Altin, C.; Sade, L.E.; Demirtas, S.; Karacaglar, E.; Kanyilmaz, S.; Simsek, V.; Ayhan, A.; Muderrisoglu, H. Effects of Paclitaxel and Carboplatin combination on mechanical myocardial and microvascular functions: A transthoracic Doppler echocardiography and two-dimensional strain imaging study. Echocardiography 2015, 32, 238-247. [CrossRef]

26. Abu-Khalaf, M.M.; Safonov, A.; Stratton, J.; Wang, S.; Hatzis, C.; Park, E.; Pusztai, L.; Gross, C.P.; Russell, R. Examining the cost-effectiveness of baseline left ventricular function assessment among breast cancer patients undergoing anthracycline-based therapy. Breast Cancer Res. Treat. 2019, 176, 261-270. [CrossRef]

27. Peddi, P.; Master, S.R.; Dwary, A.D.; Ravipati, H.P.; Patel, A.H.; Pasam, A.; Katikaneni, P.K.; Shi, R.; Burton, G.V.; Chu, Q.D. Utility of routine pretreatment evaluation of left ventricular ejection fraction in breast cancer patients receiving anthracyclines. Breast $J$. 2019, 25, 62-68. [CrossRef] [PubMed]

28. Truong, S.R.; Barry, W.T.; Moslehi, J.J.; Baker, E.L.; Mayer, E.L.; Partridge, A.H. Evaluating the Utility of Baseline Cardiac Function Screening in Early-Stage Breast Cancer Treatment. Oncologist 2016, 21, 666-670. [CrossRef]

29. O'Brien, P.; Matheson, K.; Jeyakumar, A.; Anderson, K.; Younis, T. The clinical utility of baseline cardiac assessments prior to adjuvant anthracycline chemotherapy in breast cancer: A systematic review and meta-analysis. Breast Cancer Res. Treat. 2019, 174, 357-363. [CrossRef]

30. Matsuzawa, Y.; Sugiyama, S.; Sumida, H.; Sugamura, K.; Nozaki, T.; Ohba, K.; Matsubara, J.; Kurokawa, H.; Fujisue, K.; Konishi, M.; et al. Peripheral endothelial function and cardiovascular events in high-risk patients. J. Am. Heart Assoc. 2013, 2, e000426. [CrossRef]

31. Shechter, M.; Matetzky, S.; Arad, M.; Feinberg, M.S.; Freimark, D. Vascular endothelial function predicts mortality risk in patients with advanced ischaemic chronic heart failure. Eur. J. Heart Fail. 2009, 11, 588-593. [CrossRef]

32. Kirchmair, R.; Walter, D.H.; Ii, M.; Rittig, K.; Tietz, A.B.; Murayama, T.; Emanueli, C.; Silver, M.; Wecker, A.; Amant, C.; et al. Antiangiogenesis mediates cisplatin-induced peripheral neuropathy: Attenuation or reversal by local vascular endothelial growth factor gene therapy without augmenting tumor growth. Circulation 2005, 111, 2662-2670. [CrossRef]

33. Yoshikawa, A.; Saura, R.; Matsubara, T.; Mizuno, K. A mechanism of cisplatin action: Antineoplastic effect through inhibition of neovascularization. Kobe J. Med. Sci. 1997, 43, 109-120. [PubMed]

34. Belotti, D.; Vergani, V.; Drudis, T.; Borsotti, P.; Pitelli, M.R.; Viale, G.; Giavazzi, R.; Taraboletti, G. The microtubule-affecting drug paclitaxel has antiangiogenic activity. Clin. Cancer Res. 1996, 2, 1843-1849. [PubMed]

35. Sandoo, A.; Kitas, G.D.; Carmichael, A.R. Endothelial dysfunction as a determinant of trastuzumab-mediated cardiotoxicity in patients with breast cancer. Anticancer Res. 2014, 34, 1147-1151. [PubMed] 
36. Wolf, M.B.; Baynes, J.W. The anti-cancer drug, doxorubicin, causes oxidant stress-induced endothelial dysfunction. Biochim. Biophys. Acta 2006, 1760, 267-271. [CrossRef]

37. Giordano, P.; Muggeo, P.; Delvecchio, M.; Carbonara, S.; Romano, A.; Altomare, M.; Ricci, G.; Valente, F.; Zito, A.; Scicchitano, P.; et al. Endothelial dysfunction and cardiovascular risk factors in childhood acute lymphoblastic leukemia survivors. Int. J. Cardiol. 2017, 228, 621-627. [CrossRef]

38. Ciccone, M.M.; Iacoviello, M.; Puzzovivo, A.; Scicchitano, P.; Monitillo, F.; De Crescenzo, F.; Caragnano, V.; Sassara, M.; Quistelli, G.; Guida, P.; et al. Clinical correlates of endothelial function in chronic heart failure. Clin. Res. Cardiol. 2011, 100, 515-521. [CrossRef]

39. Scicchitano, P.; Cortese, F.; Gesualdo, M.; De Palo, M.; Massari, F.; Giordano, P.; Ciccone, M.M. The role of endothelial dysfunction and oxidative stress in cerebrovascular diseases. Free Radic. Res. 2019, 53, 579-595. [CrossRef]

40. Li, X.; Lin, Y.; Zhang, R. Associations between endothelial nitric oxide synthase gene polymorphisms and the risk of coronary artery disease: A systematic review and meta-analysis of 132 case-control studies. Eur. J. Prev. Cardiol. 2019, 26, 160-170. [CrossRef]

41. Mensah, S.A.; Nersesyan, A.A.; Ebong, E.E. Endothelial Glycocalyx-Mediated Intercellular Interactions: Mechanisms and Implications for Atherosclerosis and Cancer Metastasis. Cardiovasc. Eng. Technol. 2021, 12, 72-90. [CrossRef] 